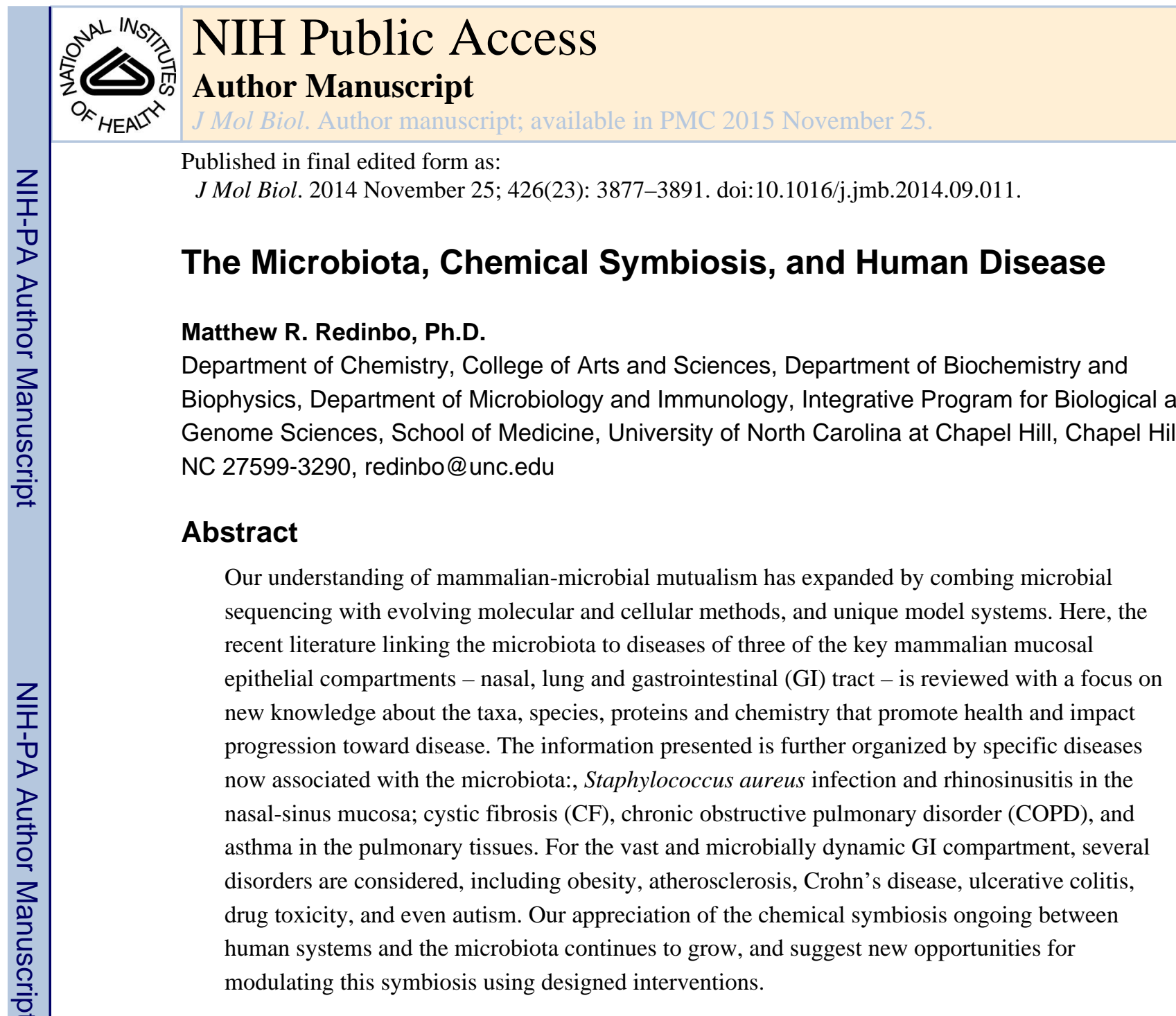

\title{
INTRODUCTION
}

Focusing on literature from the past five years, this review will consider three of the central "inside out" mucosal epithelial membrane-containing compartments relevant to mammalianmicrobial mutualism: the nasal-sinuses, the lungs, and the gastrointestinal tract (GI). Each region is involved in constant and essential chemical communication between the local microbiota and both local and systemic tissues critical to human physiology. Furthermore, each compartment can be considered as a simple system, with overall sources of input and output, as well as local give-and-take occurring between the mammalian and microbial cells at the epithelial surface; the figures in this review attempt to represent these basic systems (Figures 1-3). The goal is to provide a framework to understand the chemical, macromolecular, cellular, tissue, and systemic relationships between components of the three domains of life that coexist within the human body, although only bacterial and mammalian cells are considered here. Sections are also organized by disease states related to roles the microbiota play in human health. This review is not intended to be comprehensive, however, neither in the complexity of the tissue systems considered, nor in its coverage of the primary literature from the past five years. As an example, the oral oropharynx and subgingival crevice tissues, which interact intimately with the microbiota, are not covered. Key reviews on several topics will be cited to provide access to more comprehensive 
information. The disease states associated with the microbiota and considered here are Staphylococcus aureus infections and rhinosinusitis within the nasal-sinus compartment; cystic fibrosis (CF), chronic obstructive pulmonary disorder (COPD) and other non-asthma pulmonary disorders, and allergic asthma in the lung compartment; and the following disorders related to the GI and its resident bacteria: obesity, atherosclerosis, ulcerative colitis, Crohn's disease, autism, and drug- and xenobiotic-toxicity.

Sequencing efforts have provided organized and highly evolving data that significantly expand our understanding of the locations and activities of human symbiotic microbes ${ }^{1}$. In 2012, Human Microbiome Project reported results from 242 healthy U.S. adults sampled three times from $15-18$ body site. These efforts revealed 5,177 bacteria taxa from 16S rRNA sequencing, as well as $3.5 \mathrm{Tbp}$ of metagenomic sequencing data, including the assembled sequences of 800 reference bacterial strains ${ }^{2}$. Considerable data continue to be added to such resources, which are publicly available both in readily annotated and in pre-annotation forms. Some very general conclusions that can be drawn from the initial data analyses are that healthy people differed in bacterial composition at these body sites, but that a baseline for the Western microbiome (the genetic material present in commensal microbiota) could be defined, and that ethnic-racial clinical trends correlated with distinctions in microbial compositions 1,2 .

On an individual basis, prior work had indicated that bacterial composition is unique to each body part, significantly changes with time in each individual during infancy and early childhood, and, as born out in more detail by the HMP, compositions are distinct individual to individual ${ }^{3}$. Perhaps not surprisingly, the skin's $\sim 1.7 \mathrm{~m}^{2}$ surface area appears to host the most diverse microbiota, as it has a myriad of ways by which it samples the bacteria present in our environment. In terms of volume and number of cells, however, the human GI's $~ 250$ $\mathrm{m}^{2}$ surface is home to trillions of bacterial cells and is by far the largest and most intimate connection between cells from both domain of life. The lungs are the next largest surface area, at $\sim 85 \mathrm{~m}^{2}$, and is capable of containing a volume of $6 \mathrm{~L}$; the lungs are not abiotic, even in the lower airways, as outlined below. Finally, the relatively small $0.02 \mathrm{~L}$ volume of the nasal and paranasal cavities are populated by a distinct set of bacteria and potential pathogenic microbial species. This review will start with the smallest compartment considered here, the nasal/sinuses, then transition to pulmonary system, and finally to the large, dynamic and robustly populated GI.

\section{NASAL-SINUS COMPARTMENT}

The nasal cavities are portals to the lungs, and to some extent, the GI. They are a passthrough with mucosal membranes that contend with an onslaught of particulate and microbial material with each breath (Figure 1). A minor but important component of the nasal output is the GI, where mucin-entrapped particles are often sent for excretion. The nasal passages are clearly a key site of human viral and bacterial infection. The paranasal sinuses are also non-sterile and play enigmatic roles in physiology, and are similarly subject to viral and bacterial infection. An important component of the local, tissue-specific secretions essential for nasal function, as well as the functions of all the compartments considered here, are mucin-producing cells of each epithelial layer. 


\section{Nasal Microbiota and Staphylococcus aureus}

While $\sim 30 \%$ of humans are carriers of Staphylococcus aureus in their nasal/pharynx, it is usually not pathogenic in healthy subjects. One early human study in 2000 demonstrated that the nasal microbiota are distinct from that of the pharynx, and are distinct between individuals ${ }^{4}$. They defined a set of nasal bacterial genera (specifically Corynebacterium, Aureobacterium, Rhodococcus, and several representative Staphylococci, including $S$. epidermidis, S. capitis, S. hominis, S. haemolyticus, S. lugdunensis and S. warneri), and pointed to the presence of opportunistic pathogens. Furthermore, they concluded that certain species can dominate specific regions of the nasal mucosa, and that dominance appeared to be linked to the presence of a specific enzyme, IgA1 protease, produced by successful species. In 2004, it was shown in rats that the ability of the immune system to respond to the presence of a specific microbe, Mycoplasma pulmonis, is dependent on the presence of the normal nasal microbiota ${ }^{5}$. The results obtained are akin to the wealth of data now in place related to the GI healthy commensal bacteria and its role in establishing and regulating a healthy immune response, as outlined below.

More recent human clinical data have demonstrated that normal subjects have a diverse set of nasal microbiota dominated by the Actinobacteria, such as Propionibacterium and Corynebacterium, and Firmicutes, while hospitalized patients were enriched in both $S$. aureus and S. epidermidis, and reduced in Actinobacteria ${ }^{6}$. Furthermore, levels of $S$. aureus and $S$. epidermidis were anti-correlated, suggesting that $S$. aureus either outcompetes $S$. epidermidis, or that $S$. aureus fills nasal mucosal niches vacated by S. epidermidis. Lemon and colleagues showed in 2010 that the microbiota of the nostrils in normal human subjects showed similarities to skin in terms of the presence of Actinobacteria and Firmicutes, suggesting these portals to the nasal cavity experience a similar "onslaught" of particulate and microbial visitors, most of which can be eliminated or marginalized using mucus secretions ${ }^{7}$. These authors also found in co-culturing studies that the success of Firmicutes like $S$. aureus was associated with a failure of Actinobacteria colonization. A relatively comprehensive study in 2013 of more than 32,200 patients from several EU countries found that $S$. aureus colonization appeared in the nasal compartment of $22 \%$ of subjects examined, but that methicillin-resistant S. aureus (MRSA) was relatively rare and genetic heterogeneity existed between the MRSA strains recovered ${ }^{8}$.

Relman and colleagues took nasal microbiota composition to the next level in terms of defining specific regions of the nasal compartment and their different microbial colonization ${ }^{9}$. Healthy human subjects either carrying or not carrying $S$. aureus were sampled at three sites, the anterior nares, middle meatus, and sphenoethmoidal recess, and distinct microbial compositions were observed ${ }^{9}$. With respect to $S$. aureus, two Corynebacterium species, C. accolens and C. pseudodiptheriticum, were found to associate with the presence and absence, respectively, of $S$. aureus, and interactions between these Actinobacteria and Firmicute species were evident from laboratory co-culture studies. Finally, competition between the S. aureus and Corynebacterium only appeared evident in locations in the nasal mucosa containing ciliated pseudostratified columnar epithelia. Taken together, these recent data drive toward a detailed knowledge of both the location of key microbiota in this human mucosal compartment, and direct competitive interactions that 
occur between species that appear to help explain the relative success of genera in specific tissue niches. It is expected that more extensive co-culturing studies will reveal additional insights, and facilitate the screening for chemical and cellular interactions between bacteria species relevant to impacting local nasal health and systemic immune function.

\section{Nasal Microbiota and Rhinosinusitis}

An association between the local and even non-local microbiota in the nasal cavities and chronic rhinosinusitis (CRS) is now emerging. Microbes in the gut affect the development of a healthy immune system associated with asthma and allergy by engaging the immune Thelper 1 (Th1), Th2, Th17, as well as T-regulatory $\left(\mathrm{T}_{\mathrm{reg}}\right)$ and dendritic cells (DCs), and Toll-like receptors (TLRs) ${ }^{10}$. Recent human data have indicated that CRS with nasal polyps (CRSwNP) is dominated by a Th2 phenotype, and that there exists an association between CRS and the presence of local S. aureus in the nasal and paranasal sinuses ${ }^{10}$. To date, no relationship has yet been identified between GI microbiota and CRS, although how particulate matter and the commensal and non-commensal microbiota impact CRS is an area for new study.

Clinical data have demonstrated that, while the microbiota in CRS and normal subjects are not significantly different, the levels of immune system responses were notably higher in CRS patients relative to healthy volunteers ${ }^{11}$. CRS patients were found to have normal nasal commensal microbiota, but to exhibit increased levels in nasal lavage solutions of several cytokines, as well as eosinophils and basophils. Furthermore, peripheral blood leukocytes from CRS patients produced IL-5 in response to standard commensals, while those from non-CRS volunteers did not. Taken together, these data indicate a hyperresponse to the microbiota in the individuals with CRS, and that this response is not localized only in the nasal-sinus tissues. It will be interesting to know if host factors, including secreted proteins, somehow mediate the response to bacterial macromolecules.

Such a candidate factor would be human SPLUNC1, ${ }^{1213}$ a secreted protein whose levels are decreased in CRS.

\section{Sinus Microbiota and Rhinosinusitis}

While the nasal cavity is considerably more exposed to bacterial and particulate onslaughts than the sinuses, the paranasal sinuses are not abiotic. Indeed, the resident commensal bacterial load, diversity, and its interaction with human tissues through the sinus mucosal membranes are expected to be, like many other site in humans, critically involved in disease. Lynch and colleagues recently demonstrated that less microbial diversity was present in the sinuses of CRS patients relative to healthy controls, and that CRS patients had reduced levels of lactic acid bacteria and an increase in Corynebacterium tuberulostearicum ${ }^{14}$. The normal nasal microbiota are expected to protect against $C$. tuberulostearicum colonization; indeed, it was demonstrated that the presence of Lactobacillus sakei decreased sinus infections by $C$. tuberulostearicum, a particularly interesting result in the context of understanding how individual members of the normal microbiota compete against a single potential pathogenic species. More sinus microbial diversity, but still less than normal, was noted in samples taken from CRS patients ${ }^{15}$. In this study, Propionibacterium acnes was highest in normal subjects, while Staphylococcus aureus was highest in those with CRS. 
Here again, detailed co-culturing studies may help to clarify the molecular bases for these distinct microbial ecologies in different clinical groups.

A report this year examined the presence of extracellular vesicles (EV) derived from bacteria, which have been associated with acute inflammatory states, as well as bacterial loads from CRS, CRSwNP, and normal subjects ${ }^{16}$. Here, more bacteria but less diversity was found with CRS patients, and that levels of Bacteroides and Prevotella species were decreased, while the Proteobacteria and Staphylococcus aureus were increased. Indeed, in CRSwNP, both Staphylococcus aureus and its EV were increased relative to patients with only CRS. These data draw an increasingly detailed picture of how the sinus and nasal microbiota are associated with inflammation of the tissues in this region of the human body. This is an important area for future studies due to the prevalence of rhinosinusitis and CRS in the developed world. Also, given the relative ease with which small molecule therapeutics and/or pre- or probiotic treatments could be delivered to the nasal-sinus tissues, treating disorders in this compartment might be an avenue for success in translating basic discoveries into practice.

\section{LUNG COMPARTMENT}

\section{Overview}

Like the nasal and sinus cavities, the pulmonary airways are subject to constant exposure to particulate, environmental, and microbial threats, all of which must be kept in check to ensure proper lung function. Where the pulmonary tissues differ from the nasal passages in our compartmental view is that the lungs are a closed macro-compartment, with only a single entry and exit portal - the upper airways. Furthermore, the lower airways have the essential role in exchanging gases. Like in the nasal cavities, mucus is crucial in protecting the airways from particulate stresses, and in keeping commensal microbiota at a safe distance from the pulmonary epithelium. Additionally, the airway surface liquid that covers the lung epithelial tissues is critical, and its levels, akin to those of secreted mucus, must be tightly regulated ${ }^{17}$. The lung contains its own microbiota and both these local microbes, and microbiota located at distant body sites like the GI, may be crucial for proper lung function, as outlined below. The lung contains a larger volume and surface area than the nasal-sinus cavities (Figure 2).

It was recently shown that the general immune response to respiratory influenza viral infection requires the commensal bacteria ${ }^{18}$. In mice with normal commensals, viral infection leads to IL-1 $\beta$ and IL-18 production through activation of TLRs and inflammasomes, resulting in properly primed T-cells and dendritic cell migration to the draining lymph nodes. Lack of microbiota disrupts this normal response upon viral challenge. Indeed, germ-free (GF) mice were found in 2012 to have a build-up of invariant natural killer T cells (iNKTs) in both the lungs and the lamina propia of the colon ${ }^{19}$. iNKTs in either site are associated with increased morbidity in the inflammatory diseases of the lung (asthma) or GI (ulcerative colitis). Providing GF mice with normal commensals led to a decrease in iNKTs and decreased pathology. Thus, it would appear that the immune system must experience normal commensals at the right time in development or else a set of 
undifferentiated $\mathrm{T}$ cells will respond inappropriately when challenged with irritants in the pulmonary or GI tissues.

The connections between the lung and the GI microbiota are becoming deeply appreciated, particularly with the goal of understanding how perturbations in lung microbial composition and function should be monitored ${ }^{20}$. Along these lines, Weidmen and colleagues examined 29 human volunteers to determine how oral microbiota that make it into the airways impact pulmonary inflammation ${ }^{21}$. They measured inflammatory markers in bronchoalveolar lavage samples, as well as exhaled nitrous oxide (NO), and employed 16S rRNA sequencing. They found that patients with increased levels of Veillonella and Prevotella, taxa associated with larynx, demonstrated higher measures of lung inflammation. Such approaches could be extended beyond this small initial study toward the goal of screening for dysbiosis related to lung inflammatory diseases.

\section{Lung Microbiota and Cystic Fibrosis}

Because of the lethality of bacterial pathogens to cystic fibrosis (CF) patients, special emphasis is well placed on understanding how the microbiota of the CF lung relates to those of healthy volunteers. Years of cultivation data have established the importance of several pathogens, including $H$. influenzae, S. aureus, P. aeruginosa, Burkholderia spp. and Stenotrophomonas maltophila, but more recent work is revealing information on new bacteria not previously associated with CF exacerbations. A recent report showed that the lung microbiota of CF patients included the well known opportunistic pathogens Pseudomonas aeruginosa and Burkholderia cenocepacia, but also species of Prevotella, Streptococci, Rothia and Veillonella ${ }^{22}$. Generally, lack of microbial diversity correlated with poor lung function, but, interestingly, these authors found that antibiotic use did not appear to decrease this diversity. Other reports have also indicated that lower diversity in both bacteria, as well as fungi, in the lungs of CF patients was associated with poor lung function ${ }^{23,24}$.

Whole genome sequencing is also being employed to study CF lung colonization and potential dysbiosis. As reported this year, shotgun sequencing was used to examine sputa from two CF patients collected by several extraction techniques, and provided similar results ${ }^{25}$. Primary taxa observed in these patients were Haemophilus and Staphylococcus, along with Streptococcus, with lower levels of the following taxa detected: the anaerobic Veillonella, Prevotella, and Fusobacterium, and the aerobic Gemella, Moraxella, and Granulicatella species. In this report, though, little evidence for fungi was detected. Such results provide initial interesting clues regarding the microbiota of the CF lung, but considerable additional work is now required to understand at the cellular and molecular levels how the altered tissues and airway surface liquid (ASL) in CF patients are impacted by both normal and pathogenic bacteria.

A unique and highly interesting twist to the typical focus on the CF pathogen Burkholderia cenocepacia has been provided by Lieberman, Kishony and colleagues in two papers that focused on Burkholderia dolosa. This is typically a soil bacterium, but based on this work is now appreciated as an late-stage CF pathogen. This team followed the allelic trajectories of a deadly pathogenic outbreak in 14 patients over an impressive 16-year period, and was able 
to identify specific mutations acquired in $B$. dolosa genes over this time frame that were indicative of adaptive evolution. Alternations were seen in antibiotic resistance genes, membrane composition factors, iron scavenging, and oxygen sensitive genes, some of which may provide potential new targets for therapeutic intervention ${ }^{26}$. Furthermore, B. dolosa cells with mutations coexist with those lacking mutations in the lungs of the same patient over years ${ }^{27}$. Thus, even under strong selective pressure, adaptive mutations do not take over, suggesting that the overall mosaic community of $B$. dolosa, and likely the full complement of the microbiota present in these tissues, "crowd source" the job of surviving in the lungs of patients. An area of particularly exciting future work will be in defining the chemical basis of this coexistence and mutualism within these patients, and in healthy individuals as well.

\section{Lung Microbiota, COPD, and Other Non-Asthma Diseases}

Defining the lung microbiota associated with chronic obstructive pulmonary disorder (COPD) and other non-CF or -asthma lung diseases has also been progressing ${ }^{28}$. This is particularly important for COPD, which is the third-leading cause of death worldwide ${ }^{29}$. A 2011 study examined healthy patients, non-COPD smokers, and COPD patients, and found the COPD group exhibited a limited bacterial community diversity and microscopic differences in the anatomical distribution of bacteria ${ }^{30}$. A core lung microbiota was considered to be composed of Pseudomonas, Streptococcus, Prevotella, Fusobacterium, Haemophilus, Veillonella, and Porphyromonas species. Hilty and colleagues found last year that the lower airways consisted of a set of Prevotella, Streptococcus and Acidaminococcus species, but that no significant difference was seen in the overall composition in this area between healthy subjects and those with interstitial lung disease ${ }^{31}$. However, diseased lungs showed distinctions in localization of Haemophilus influenzae, as well as S. pneumoniae, the Neisseriaceae, and the Cellulomonadaceae. Thus, it appears that often it's not what microbes are present, but where they are lurking that matters both in the lungs, and likely elsewhere.

How does rhinovirus infection impact the lung microbiome? In a study of COPD and healthy patients after viral infection, only the COPD patients showed a large increase in bacteria, particularly in Proteobacteria, and in $H$. influenzae ${ }^{32}$. These changes persisted for more than 40 days after infection, at least within the sputum samples examined. In contrast, there was stability in normal subjects, both smokers and non-smokers. These results indicate that COPD patients who acquire a head-cold can experience profound and long-term changes in their lung microbiota, giving $H$. influenzae a chance to take hold.

Even more recent data suggest that particular measures of sputum IL-1 $\beta$ and IL-18, as well as serum C-reactive protein (CRP), can be indicative of $H$. influenzae presence in non-CF lung disease patients ${ }^{33}$. Levels of $P$. aeruginosa, $H$. influenzae and other bacteria in these patients provided a useful stratification indicative of patient outcomes. Specifically, $P$. aeruginosa and $H$. influenzae dominance correlated with poorer lung function and higher interleukin and CRP levels. P. aeruginosa, along with Veillonella species, were also indicative of future exacerbations of lung function. Such data indicate that measures of both host responses and key microbiota composition can be used clinically to evaluate patients at risk for pulmonary failure. 


\section{Lung Microbiota and Asthma}

It was shown in 2004 that disruption of the GI microbiota with antibiotics, followed by the introduction of a fungal pathogen (C. albicans) into the GI, led to allergic responses in the pulmonary tissues of mice when challenged with the mold spore Aspergillus fumigatus ${ }^{34}$. Without GI antibiotics, mice challenged with fungi in the same way did not develop increases in eosinophils, mast cells, interleukins, and mucus-secreting cells in the airway. Thus, early links to GI microbiota and lung allergic responses were established, and those GI-systemic connections are now extending to many other areas of homeostasis and disease. It has been shown that some allergic asthmatics contain more Proteobacterial Haemophilus species, akin to the disrupted microbiota of COPD patients, as well as less Bacteroidetes, particularly Prevotella, than healthy controls ${ }^{35}$.

Children on farms have less likelihood of developing asthma, and it is now known that such children are exposed to more bacteria, more bacterial diversity, and more fungal diversity than their counterparts raised in non-farm environments ${ }^{36}$. The bacteria farm children tend to see more include Listeria monocytogenes, Bacilli, and the Corynebacteria. These data support the conclusion that proper control of future inflammatory responses in the lung are dependent on experiencing microbial diversity at key stages during development and early childhood, as well as solid continual exposure throughout life. For example, evidence exists that the presence of the stomach-associated microbe Helicobacter pylori, particularly CagApositive strains, is protective against childhood asthma in part by the gastric recruitment of regulatory T-cells ${ }^{37}$.

House dust (HD) is a common lung-specific exacerbating factor in asthma airway hyperresponsiveness (AHR). Regular low dose HD exposure can reduce AHR and reduce T helper cell 2 (Th2) cytokine production in response to future challenges, and that this modulation of immune response is dependent on the presence of a healthy microbiota ${ }^{38}$. Subsequent data have now established that mice exposed to HD accumulate fewer airway Tcells, experience attenuated Th2-related airway responses, and have a reduction in mucin production ${ }^{39}$. In these animals, the GI, not lung, microbiota were found to change, especially in increases in Lactobacillus johnsonii. Simply giving L. johnsonii to animals, remarkably, appears to be sufficient in some respects, as these animals are protected in terms of their responses to HD or viral challenges, with lower activated CD8 and CD11 cells, and reduced Th2 cytokine production. These results link airway asthma to GI bacteria, and highlight $L$. johnsonii as a potential causative species in this interplay.

However, it would appear that it's not simply the bacteria, nor environmental allergen triggers like HD, that tune the immune system toward a properly modulated response to pulmonary irritation. This is also dependent on the metabolic activity of the GI microbiota. As shown this year, dietary fiber content changed the GI and the lung microbiota in mice, shifting the Firmicutes:Bacteroidetes ratio ${ }^{40}$. In the GI, the increase in Firmicute species processed high fiber content and generated circulating short chain fatty acids (SCFAs), which were protective against allergic asthma response in the lung. Indeed, simply providing mice the SCFA propionate leads to altered bone marrow hematopoiesis, more macrophage and dendritic cell (DC) precursors, and more DC precursors in the lungs that could act as 
phagocytes and impair the activation of Th2 cell effector function. In short, at least in mice, what they eat impacts how their lungs react. Our understanding of the connection between the GI macrocompartment and the pulmonary tissues continues to grow, and highlights how crucial the GI is to immune responses in the lungs and throughout the body.

\section{GASTROINTESTINAL COMPARTMENT}

\section{Overview}

The GI is by far the largest microbial compartment in the body, with trillions of bacterial cells residing in the adult human intestinal tract. This region also contains the largest surface area in the human body, with the villi and microvilli of the small bowel in particularly creating the vast $\sim 250 \mathrm{~m}^{2}$ surface the dwarfs that of the skin, sinuses, nasal cavity and lungs. The GI experiences two significant inputs - food through the esophagus, and bile and other secretions from gall bladder, pancreas and other small proximal organs (Figure 3). As such, the GI acts as an enormous bioreactor for processing sources of energy, as well as chemical and biological threats that enter this compartment. Importantly the GI selects, through its mucosal epithelium, what materials are brought from the outside in. At its terminus, of course, is the major output portal of the GI, although a tremendous amount of fluid is absorbed both in the small, and more so, in the large intestines, prior to concentration in the feces for elimination.

Here, an attempt is made to focus on recent literature regarding the microbiota and several human diseases related to diet and obesity, atherosclerosis, Crohn's disease, ulcerative colitis, autism, and drug- and xenobiotic-processing. A further goal of this section is to highlight specific bacterial species and/or microbial and host factors shown to be involved in this most complex and dynamic arena of mammalian-microbiota mutualism.

A recent paper that examined individuals from the HMP studied the microbiota in the GI from ten different sample points along this organ, and clustered them into four overall groups by location site and compositional correlation ${ }^{41}$. Their results further our appreciation that metabolic activity can be vary considerably between sites, noting in particular the higher activities in the oral and stool regions for both sugar utilization and hydrogen sulfide $\left(\mathrm{H}_{2} \mathrm{~S}\right)$ production. Thus, we are beginning to understand the specific chemical, metabolic, and enzymatic differences between the microbiota in distinct regions of this complex compartment. More generally, 16S rRNA sequencing and whole genome sequencing of 500 cultured isolates from 37 US adults over 5 years has shown that strains are resident for decades, and that related people have related GI microbiota ${ }^{42}$. Changes in composition were observed, though, during weight loss, indicating the dynamic nature of the microbiota when the inputs into the GI are significantly altered.

\section{GI Microbiota, Diet and Obesity}

The relationship between diet, obesity and the microbiota has been a particularly vigorous area of study. A 2009 report examined more than 150 lean and obese adult twins and correlated mothers, and defined a core microbiome at the gene level ${ }^{43}$. Obesity was linked to changes in microbiota, reduced bacterial diversity, and changes in microbial expression of a variety of different KEGG (Kyoto Encyclopedia of Genes and Genomes) enzyme classes, 
including those involved in carbohydrate, lipid, and amino acid metabolism. One distinction observed was that expression glycosyltransferase enzymes between lean and obese twins were similar, but expression of glycosylhydrolase enzymes, which are employed to harvest energy from various dietary sources, varied between these two groups. These effects are likely driven by differences in diet as well as microbial composition in the GI. Results from future larger, longitudinal studies will be of considerable interest to validate and extend these initial findings.

Sonnenburg and colleagues focused in 2010 on a specific dietary component, the fructans, and showed that these compounds lead to the proliferation of particular species of Bacteroides ${ }^{44}$. They further defined a two-component signaling sensor that controls the fructan utilization locus in Bacteroides thetaiotaomicron (B. theta.), and they found that the locus varies in Bacteroides in a manner that predictably reflects variability in fructan processing. Finally, at the molecular level, they established that the presence of a particular enzyme, $\beta$-2-6-endofrucanase, allows $B$. theta. to employ and metabolize, $\beta$-2-6-linked fructans like levan. This arc from dietary components, through GI microbial composition, into bacterial transcriptional control, and finally to specific catalytic activities demonstrates the power of our current ability to unravel details of mammalian-microbial chemical symbiosis.

The same group also examined the ability of the GI microflora to process milk saccharides ${ }^{45}$. They found that, during early colonization in mice, B. theta. and B. fragilis employ a set of genes usually reserved for the degradation of host mucus glycans. Instead, in this study, these factors were employed to process the human milk oligosaccharides (HMOs) that arrive undigested in the distal GI. Mucus glycans are similar, but not identical to HMOs. Indeed, they showed that one HMO-specific glycan, lacto-N-neotetraose, is handled particularly well by another GI microbial species, Bifidobacterium infantis, which allows this particular bacterium to flourish in the competitive colonization environment of the infant GI. These results further advance the view of the microbiota as providing a mosaic of enzymatic capabilities designed to benefit from particular metabolic niches in the GI.

The reader is directed to a comprehensive recent review of glycan metabolism and the GI microbiota by Koropatkin and colleagues ${ }^{46}$. These authors provide great detail on the chemical nature and distribution of the carbohydrates in the GI, the microbial enzymes and species that degrade them, and a description of the mucus layers present in distinct locations in the intestinal tract. The essential role of the GI microbiota in diet and obesity was recently highlighted in a study in which intestinal bacteria were disrupted in early mouse development via sub-therapeutic levels of antibiotics ${ }^{47}$. Marked changes in metabolism were observed, and were shown to cause an increase in animal fat mass and obesity. At the molecular level, increased carbohydrate to short-chain fatty acid ratios were associated with changes in microbial gene expression, and changes in the regulation of hepatic metabolism lipids and carbohydrates were also observed in the host.

We clearly need our natural intestinal microflora, not just for proper energy metabolism, but also for keeping pathogenic microbes at bay. Bacterial pathogens commonly employ virulence genes to initiate a colonizing infection at the GI epithelium but then, once 
established, they typically must shift from the epithelium to the GI lumen to compete for carbohydrate sources of energy. In the healthy GI, though, such potential pathogens are outcompeted in the lumen by the non-pathogen symbiotic bacteria that thrive there. This was recently demonstrated in elegant detail in germ-free animals lacking an intact GI microbiota ${ }^{48}$. Thus, commensals usually promote pathogen elimination by ousting the nascent pathogens through more efficient carbohydrate metabolism.

More details on how the disruption of normal microbiota impacts pathogen proliferation was provided in 2013, when it was shown that Salmonella and Clostridium difficile employ unique and distinct strategies of using the mucosal glycans liberated by the healthy microbiota ${ }^{49}$. Salmonella utilizes fucose and sialic acid obtained from the lumen, and relies on a specific set of its own genes to do so. $C$. difficile, in contrast, scavenges for sialic acid produced, but tossed aside, by $B$. theta. sialidases. Thus, pathogens can employ what healthy commensals leave behind. Such data point to specific genes in Salmonella and C. difficile that are essential for expansion of these pathogens during GI infections, and suggest that other gene products might be found in other potential pathogens in the GI.

Time, of course, matters, too. Diet, drugs, and other compounds can modify not only GI microbial composition but also transit time, an important factor in this dynamic compartment. For example, increasing the rate by which material transits the mouse GI was shown to decrease levels of Peptococcaceae, Eubacteriaceae, and Anaeroplasmataceae, and to the relative increases in levels of Bacteroides and Peptostreptococcacea ${ }^{50}$. In contrast, the antidiarrheal compound loperamide was found to increase the Firmicute:Bacteroides ratio, and to significantly decrease Lachnospira taxa. Inclusion of factors that vary transit time would be an interesting addition to future studies on GI function and the microbiota.

Humans do not encode the enzymes necessary to digest most dietary fibers, so we rely on our GI microbiota to perform the saccharification and fermentation necessary to free the simple mono- and di-saccharides we need for energy generation. For example, plant cell wall xyloglucans (XyGs) are branched carbohydrates impenetrable to human systems. A complex gene locus in GI-resident Bovatus bacteria was found to process XyGs using specific gene products that encode, for example, carbohydrate binding proteins, glycoside hydrolases, and a specific endo-xyloglycanase that cleaves the XyGs into monosaccharides ${ }^{51}$. It was further found that these loci are restricted to only a few species of bacteria, but that the locus is found widely in the human gut metagenomes in-hand. As such, these data provide an excellent example of "specialization" within the GI microbiota.

Finally, an excellent and comprehensive recent report significantly advances our understanding of certain aspects of the chemistry, enzymology, and species composition of the GI microbiota and its relationship to human diet ${ }^{52}$. Human meat-eaters, which produce more bile acids, were found to contain more bile acid-tolerant Alistipes, Bilophila and Bacteroides taxa than vegans. Carnivores also exhibited decreased levels of Firmicutes, specifically Roseburia, Eubacterium rectale and Ruminococcus bromii, which efficiently process plant dietary polysaccharides. The expected converse results were observed with vegans, who were shown to contain more GI-resident plant-processing bacteria and expressed gene products. Additional intriguing and detailed data were also provided at the 
species and enzyme level. For example, Bilophila wadsworthia, which increases with meat consumption, appears to link dietary fat, bile acids and GI inflammatory responses. $B$. wads. was found to grow well upon bile acids, and to express sulfite reductases that produce the GI irritant $\mathrm{H}_{2} \mathrm{~S}$. Generally, both bile salt hydrolases and sulfite reductases demonstrated increased expression upon animal-based diets. Thus, such data set the stage for future research into the specific molecular and enzymatic dysfunctions associated with a range of GI diseases.

\section{GI Microbiota and Atherosclerosis}

Recent links between atherosclerosis and the GI microbiota have focused on trimethylamine (TMA) and enzymes expressed by both the microbes and the host. For example, dietary choline can be converted to TMA via a glycyl-radical intermediate through the actions of a set of microbial enzyme that were recently characterized in detail ${ }^{53}$. Circulating plasma levels of the TMA metabolite trimethylamine N-oxide (TMAO) created by mammalian flavin mono-oxygenases, including FMO1 and FMO3, are linked to atherosclerosis ${ }^{54}$. Bennett and colleagues showed that FMO3 expression was impacted by androgens and bile acids and controlled by circulating TMAO levels. Using deuterium-labeled eggs consumed by human volunteers with and without antibiotics, a direct link between choline and phosphatidylcholine metabolism, the GI microbiota, and TMAO was also recently established ${ }^{55}$. With antibiotics, less labeled TMAO was observed in human plasma samples, demonstrating in healthy human subjects the direct role the GI bacteria play in producing this risk marker of atherosclerosis.

L-carnitine from red meat is also metabolized by GI microbiota to TMAO, and specific bacteria were recently associated with TMAO production ${ }^{56}$. For example, Prevotella and some Clostridia species were observed more, while some Bacteroidetes and Lachnospira less, in the GI microbiota of omnivores relative to those of vegans and vegetarians. It was further found that TMAO appears to inhibit reverse cholesterol transport, and TMAO levels in an impressive $>2,500$ patients were found to be associated with CVD, myocardial infarction, stroke, and death. Thus, these data link diet to specific microbial and mammalian processes that affect cholesterol homeostasis and CVD progression.

\section{GI Microbiota, Crohn's Disease and Ulcerative Colitis}

One of the most important interactions between the GI microbiota and host systems involves innate and adaptive immunity and the control of inflammation. We know that disruptions in these processes contribute to the progression of numerous diseases, including Crohn's Disease and ulcerative colitis, and even colitis-associated colorectal cancer. To keep "our side of the street" in proper immunological check, we need tight epithelial cell junctions and a layer of protective mucus, along with a range of secreted antimicrobial peptides and IgA molecules. Furthermore, on and within our cells, we need our pattern recognition receptors, including Toll-like receptors (TLRs), inflammasome-associated nucleotide-binding domain leucine-rich repeat (NLR) proteins, and C-type lectin receptors (CLRs), which monitor specific microbial factors, like cell wall components, pili and pilus-associated proteins, flagellar factors, and nucleic acids ${ }^{57}$. These systems control our responses to our GI microbiota, and a failure to control these responses properly appears to significantly 
contribute to the disease states listed above. Indeed, mutations in the NLR Nod2 are associated with development of Crohn's disease. It was recently shown that the inflammasome-containing NLRP6 protein is required in mice for mucus secretion in the large intestine ${ }^{58}$. NLRP6 controls the exocytosis of mucin granules from goblet cells, and lack of NLRP6 eliminates proper goblet cell autophagy and mucin secretion, leading to the inability of mice to clear pathogenic bacteria.

With respect to mucosal homeostasis and GI inflammation, the antigen-presenting molecule CD1 on GI epithelial cells is known to present self and microbial lipid antigens to natural killer T-cells, (NKTs), and reductions in surface CD1 molecules leads to GI inflammation ${ }^{59}$. The mechanism of CD1's protective effects is through STAT3-dependent IL-10 production, along with HSP110 and more CD1, and all are involved in controlling inflammation. Deletions of any of these factors leads to a colitis-like pathology likely through improperly controlled inflammation. One mechanism for mammalian immune system regulation by specific bacterial-derived chemicals appears to involve glycosphingolipids. It was recently shown that a specific GI $B$. fragilis isolate produced an alpha-galactosylceramide capable of agonizing NKTs ${ }^{60}$. Furthermore, it is clear that the receipt of proper microbial signals, in the form of bacterial cellular debris, collected by GIproximal immune cells is required to produce IL-1 $\beta$, which then employs the GM-CSF from innate lymphoid cells (ILCs) to produce the proper level of regulatory T-cells $\left(\mathrm{T}_{\text {reg }}\right)$ for immune system homeostasis ${ }^{61}$. Diet also impacts local and systemic inflammation through the production of short chain fatty acids (SCFAs) like butyrate and acetate, which impact $\mathrm{T}_{\text {reg }}$ cell function 40 .

If homeostasis is disrupted through tissue injury, neutrophils are central inflammatory responders, and the microbiota are involved in controlling neutrophils in the GI. What about elsewhere in the organism? Rawls and colleagues showed that GI bacteria lead to increases in serum amyloid A protein and NF- $\mathrm{kB}$ activation, and then to the subsequent neutrophil increases and migration to tissue injury sites ${ }^{62}$. Direct connections between diet, bile acid conjugation in the liver, and GI bacteria that lead to inflammation were provided in $2012{ }^{63}$. High-milk-fat fed mice showed increased GI levels of $B$. wads., a potential pathogen that produces $\mathrm{H}_{2} \mathrm{~S}$. Proinflammatory T helper type 1 cells (Th1) increase as a result, and this leads to colitis in IL-10-knockout mice. The molecular pathway appears to involve the production of taurineconjugated bile acids in the liver, which when sent to the GI provides more sulfur to $B$. wads. in the dysbiotic GI, and the sulfur is used by this species to produce more GI-damaging $\mathrm{H}_{2} \mathrm{~S}$.

The microbiota are involved in colitis-associated colorectal cancer (CRC). In the inflammatory state associated with CRC, increases in Proteobacteria were observed ${ }^{64}$. Furthermore, if IL10-knockout mice are colonized with normal Escherichia coli, they develop CRC. Removal of the polyketide synthase (PKS) genotoxic island from E. coli, however, leads to less CRC in IL-10-knockout mice without impacting inflammation. Thus, inflammation appears to allow bacteria capable of producing toxic compounds, like those generated by the E. coli $\mathrm{PKS}$, to become isolated in particular sub-niches of the GI, and to promote subsequent neoplastic phenotypes. Indeed, PKS-containing bacteria are known to be associated with the mucosa of patients with CRC. 


\section{GI Microbiota and Autism}

Even the incredibly complicated etiology of autism is now preliminarily linked to the GI microbiota. Using a mouse model that reflects symptoms of autism, researchers noted gastrointestinal barrier function defects and microbial dysbiosis ${ }^{65}$. However, they found that providing $B$. fragilis to these mice early in development reduced their autism-like behavior. They further showed that elevations in GI-produced 4-ethylphenylsulfate (EPS) were directly linked to symptoms of autism in mice. Providing EPS, which was elevated more than 40-fold in the mice with autism-like symptoms, to normal mice resulted in some of the behavior abnormalities associated with the autistic model mice. Such data intriguingly highlight the intimate communication at play between our GI-resident bacteria and the systems that control our neurodevelopment and behavior, but await further validation in future studies.

\section{GI Microbiota, Drugs and Xenobiotics}

It has been known for decades that the microbiota, particularly in the GI, can play a significant role in the efficacy and elimination of drugs and other xenobiotic compounds ${ }^{66}$. Recent data have provided an exceptional framework for understanding how therapeutic reagents can impact the GI microbiota. Maurice and colleagues defined elegant means for distinguishing between healthy and non-healthy GI microbes, and then measured how both antibiotics and non-lethal drugs altered this equilibrium ${ }^{67}$. As expected, antimicrobial compounds significantly shifted the balance towards a less healthy GI microbiota. They found that the more highly active cells in xenobiotic-treated GIs were of the Firmicute order, while the Bacteroidetes were decreased; within the less active microbes, enrichments in Bacteroidetes, Bifidobacteria, and Lachnospiraceae were also observed. A view of familylevel gene expression data revealed that antibiotic resistance pathways were up-regulated in the presence of antimicrobial compounds. With all the therapeutics examined, increases in bacterial xenobiotic metabolism factors, as well as stress response genes, were also observed. Interestingly, these authors also linked specific microbial enzymes (reductases), transporters (for sugars and small molecules), and transcription factors that were impacted by specific drugs such as digoxin, nizatidine, sulfasalazine. Such results indicate that we are perhaps ready to examine how individual enzymes expressed by the GI bacteria can impact individual drugs.

Indeed, the same group went on to do just that, studying how the cardiac glycoside digoxin is inactivated by enzymes expressed by a single GI-resident microbial species, Eggerthella lenta ${ }^{68}$. This bacterium up-regulates the expression of a unique genetic operon in response to the presence of digoxin. The operon encodes enzymes determined to be cardiac glycoside reductases termed Cgr1 and Cgr2, both of which are homologous by sequence to bacterial cytochromes and are expected to be able to use digoxin as an alternative electron acceptor. The only difference between activated and inactivated dihydrodigoxin is the reduction of a single double-bond in the drug. Based on where these reductases are located in the metabolic network of Eggerthella, the authors predicted that the operon would be repressed by dietary arginine or dietary protein, and their results supported this hypothesis. In gnotobiotic mice and in mice provided specific diets or dietary supplements, predicted changes to serum and urinary digoxin metabolites were observed. These data support the conclusion that we can 
understand and harness the actions of single gene products in the vast and diverse GI microbiome, and that knowledge could, with considerable future development, support clinical care.

A more direct connection between specific enzymes and clinical outcomes was provided by the author and colleagues in 2010, when it was demonstrated that the GI microbiome can be selectively modulated using targeted small molecules ${ }^{69}$. The problem addressed was the acute dose-limiting toxicity of the anticancer drug irinotecan (CPT-11), a mainstay treatment in colorectal, pancreatic, and other solid and non-solid cancerous malignancies. Irinotecan is inactivated by the human sugar-conjugating UDP-glucuronosyltransferase (UGT) enzymes, the primary Phase II drug metabolism process, and these drug-glucuronic acid conjugates are sent to the GI for elimination. There, though, they are substrates for sugar scavenging $\beta$ glucuronidase enzymes expressed by the GI microbiota. These GI bacterial enzymes produce the active form of irinotecan, which kills the epithelial cells lining the large GI and generates severe diarrhea. In most cases, this side effect requires reductions in or terminations of Irinotecan treatment, resulting in losses in antitumor activity.

We identified potent and non-lethal inhibitors of bacterial $\beta$-glucuronidases that proved effective in living aerobic and anaerobic bacteria, and ameliorated Irinotecan-induced diarrhea in mice ${ }^{69}$. The non-lethality of these compounds was considered important in stopping this single catalytic activity without disrupting the microbiota essential for GI health. Furthermore, these inhibitors were highly selective for the bacterial enzymes relative to the human enzyme, which is essential for the lysosomal processing of larger glycan substrates ${ }^{70}$. Germ line disruptions of human $\beta$-glucuronidase gene causes the lethal lysosomal storage disease Sly Syndrome. These data establish that the two million genes of the microbiome, which dwarfs our human genome by 100 -fold, contains tractable therapeutic targets for unmet medical needs ${ }^{71}$.

This approach has proven effective with an orthologous group of drugs with a distinct type of GI toxicity - the NSAIDs, which produce longitudinal small intestinal ulcers in addition to their wellappreciated gastric toxicity ${ }^{72}$. It is known that $40 \%$ of fatalities caused by NSAID toxicity are due to intestinal, not stomach, damage. In mouse models of toxicity caused by three NSAIDs, diclofenac ${ }^{73}$, indomethacin ${ }^{74}$, and ketoprofen ${ }^{75}$, oral delivery of bacterial glucuronidase inhibitors significantly reduced small intestinal ulcers.

Two recent reports connect the GI microbiota, systemic immune function, and therapeutics in a highly intriguing manner. First, Iida and coworkers demonstrated that for two anticancer drugs, CpG-oligonucleotides and platinum compounds, efficacy required the commensal GI microbiota such that tumor-infiltrating myeloid-derived cells would find their way to the tumor-microenvironment ${ }^{76}$. Once in place, these immune cells generate the reactive oxygen species and other cytotoxic factors that attack the tumor. Second, it was shown that the anticancer drug cyclophosphamide works in part by the same mechanism of generating a host anti-tumor immune response. Viaud and colleagues demonstrated that cyclophosphamide requires the Gram-positive bacteria themselves to relocate to lymphoid tissues ${ }^{77}$. There, the microbes stimulate particular pathogenic T helper cells, as well as Th1 factors, that effectively tackle the tumor. Taken together, these data significantly advance 
and specify our understanding of how the innate immune system can be ramped up by antineoplastic compounds and the GI microbiota to attack tumors located at distant sites in the body. The implications of this work are both direct and indirect in terms of understanding how specific drugs might be improved, and appreciating opportunities to develop new therapeutic approaches to chemotherapy.

Finally, a 2014 paper in Immunity connects a specific metabolite, indole 3-propionic acid, produced by a specific intestinal microbe, Clostridium sporogenes, to changes in mammalian gene expression that directly impact GI integrity ${ }^{78}$. This bacterial tryptophan derivative was shown to be involved in activating the mammalian nuclear xenobiotic receptor PXR. Through PXR, this compound up-regulates the expression of proteins involved in intestinal tight junctions, and down-regulates enterocyte TNAa expression, which in turn decreases levels of the Toll-like receptor TLR4. TLR4 activates the innate immune system in response to bacterial lipopolysaccharides. Thus, these authors establish that a mammalian transcription factor is regulated by a microbial compound to keep GI barrier function intact, and to limit the immune system's response to the constant presence of bacteria in the GI. These data further deepen our appreciation of chemical mutualism at play in mammalian-microbial symbiosis, and hint at additional targets that could be modulated for therapeutic intervention.

\section{FUTURE DIRECTIONS}

With continually evolving microbiota sequencing efforts well in place, we now have vast opportunities to gain new knowledge about the microbiota and its chemical symbiosis with mammalian tissues, particularly in understanding how local and non-local disruptions in healthy mucosal epithelial-microbial interactions contribute to disease in the nasal, lung and intestinal compartments. As outlined above, it is when models of disorder, as well as studies in humans, are combined with sequencing, molecular and microbial biology, chemistry, and biochemistry that we gain our most powerful appreciation of our complex microbiota and their niches of function. Examples of important recent steps forward include identifying specific glycan-cleaving enzymes associated with energy generation ${ }^{44}$, pathogenesis 48,49 , and drug toxicity ${ }^{67}$, as well as the reductases linked to drug inactivation with digoxin ${ }^{68}$. These insights indicate that basic and applied understandings of chemical symbiosis is highly tractable, and even capable of modulation by rational small molecules ${ }^{69}$. Future studies of interest might include carefully mapping within the gastrointestinal tract, for example, longitudinal and cross-sectional changes in microbial ecology and gene expression in response to perturbations, focusing initially on already established targets of interest (e.g., see Refs. 67-69). The nasal-sinuses and upper-airways were also highlighted in this review in part because of the relative ease with which novel therapeutics might be delivered to these tissues.

From a structural and chemical biology perspective, a conceptually simple but powerfully tractable line of investigation would be the detailed characterization of the sugar-cleaving enzymes encoded by the GI microbiota. As outlined elegantly in 2010, these highly active and diverse carbohydrate-active enzymes (CAZymes) are really only present in our microbiota ${ }^{79}$. As humans, we encode only a handful, and yet we can access a huge amount 
of dietary material because of our mutualistic partners in the GI, who use a modular set of sugar-active enzymes and other systems to get what they need, before we take what they leave behind. Such approaches could also be applied to the lung and nasal-sinus compartments with respect to mucin-processing factors, for example, with an initial focus on energy generation, a key driver of relative microbial success. We started understanding biochemistry decades ago by studying metabolism, and this could continue now with efforts to map the manner in which energy utilization impacts the microbiota, the mucosal epithelia, and human health.

\section{Acknowledgments}

The author gratefully acknowledges the help provided by his collaborators Sridhar Mani, Urs Boelsterli, and Ward Peterson, and current and former members of his laboratory, particularly Adam Roberts, Julianne Huang, Rebecca Pollet, William Walton, and Bret Wallace. In addition, the author thanks Stefan Knapp and Alex Bullock at Oxford's Structural Genomics Consortium, and Robert Gilbert and Alfonso Moreno at Magdalen College, University of Oxford, for their help and support. Funding provided by the University of North Carolina Cancer Research Fund, the UNC Kenan Leave Fellowship, UNC's Department of Chemistry and Integrative Program for Biological and Genome Sciences, and the National Institutes of Health.

\section{References}

1. Methé BA, Nelson KE, Pop M, Creasy HH, Giglio MG, Huttenhower C, Gevers D, Petrosino JF, Abubucker S, Badger JH, Chinwalla AT, Earl AM, FitzGerald MG, Fulton RS, Hallsworth-Pepin K, Lobos EA, Madupu R, Magrini V, Martin JC, Mitreva M, Muzny DM, Sodergren EJ, Versalovic J, Wollam AM, Worley KC, Wortman JR, Young SK, Zeng Q, Aagaard KM, Abolude OO, AllenVercoe E, Alm EJ, Alvarado L, Andersen GL, Anderson S, Appelbaum E, Arachchi HM, Armitage G, Arze CA, Ayvaz T, Baker CC, Begg L, Belachew T, Bhonagiri V, Bihan M, Blaser MJ, Bloom T, Bonazzi VR, Brooks P, Buck GA, Buhay CJ, Busam DA, Campbell JL, Canon SR, Cantarel BL, Chain PS, Chen I-MA, Chen L, Chhibba S, Chu K, Ciulla DM, Clemente JC, Clifton SW, Conlan S, Crabtree J, Cutting MA, Davidovics NJ, Davis CC, DeSantis TZ, Deal C, Delehaunty KD, Dewhirst FE, Deych E, Ding Y, Dooling DJ, Dugan SP, Michael Dunne W, Scott Durkin A, Edgar RC, Erlich RL, Farmer CN, Farrell RM, Faust K, Feldgarden M, Felix VM, Fisher S, Fodor AA, Forney L, Foster L, Di Francesco V, Friedman J, Friedrich DC, Fronick CC, Fulton LL, Gao H, Garcia N, Giannoukos G, Giblin C, Giovanni MY, Goldberg JM, Goll J, Gonzalez A, Griggs A, Gujja S, Haas BJ, Hamilton HA, Harris EL, Hepburn TA, Herter B, Hoffmann DE, Holder ME, Howarth C, Huang KH, Huse SM, Izard J, Jansson JK, Jiang H, Jordan C, Joshi V, Katancik JA, Keitel WA, Kelley ST, Kells C, Kinder-Haake S, King NB, Knight R, Knights D, Kong HH, Koren O, Koren S, Kota KC, Kovar CL, Kyrpides NC, La Rosa PS, Lee SL, Lemon KP, Lennon N, Lewis CM, Lewis L, Ley RE, Li K, Liolios K, Liu B, Liu Y, Lo C-C, Lozupone CA, Dwayne Lunsford R, Madden T, Mahurkar AA, Mannon PJ, Mardis ER, Markowitz VM, Mavrommatis K, McCorrison JM, McDonald D, McEwen J, McGuire AL, McInnes P, Mehta T, Mihindukulasuriya KA, Miller JR, Minx PJ, Newsham I, Nusbaum C, O’Laughlin M, Orvis J, Pagani I, Palaniappan K, Patel SM, Pearson M, Peterson J, Podar M, Pohl C, Pollard KS, Priest ME, Proctor LM, Qin X, Raes J, Ravel J, Reid JG, Rho M, Rhodes R, Riehle KP, Rivera MC, Rodriguez-Mueller B, Rogers Y-H, Ross MC, Russ C, Sanka RK, Sankar P, Fah Sathirapongsasuti J, Schloss JA, Schloss PD, Schmidt TM, Scholz M, Schriml L, Schubert AM, Segata N, Segre JA, Shannon WD, Sharp RR, Sharpton TJ, Shenoy N, Sheth NU, Simone GA, Singh I, Smillie CS, Sobel JD, Sommer DD, Spicer P, Sutton GG, Sykes SM, Tabbaa DG, Thiagarajan M, Tomlinson CM, Torralba M, Treangen TJ, Truty RM, Vishnivetskaya TA, Walker J, Wang L, Wang Z, Ward DV, Warren W, Watson MA, Wellington C, Wetterstrand KA, White JR, Wilczek-Boney K, Qing Wu Y, Wylie KM, Wylie T, Yandava C, Ye L, Ye Y, Yooseph S, Youmans BP, Zhang L, Zhou Y, Zhu Y, Zoloth L, Zucker JD, Birren BW, Gibbs RA, Highlander SK, Weinstock GM, Wilson RK, White O. A framework for human microbiome research. Nature. 2012; 486:215-221. [PubMed: 22699610]

2. Mitreva M. The Human Microbiome Project Consortium. Structure, function and diversity of the healthy human microbiome. Nature. 2012; 486:207-214. [PubMed: 22699609] 
3. Costello EK, Lauber CL, Hamady M, Fierer N, Gordon JI, Knight R. Bacterial Community Variation in Human Body Habitats Across Space and Time. Science. 2009; 326:1694-1697. [PubMed: 19892944]

4. Rasmussen TT, Kirkeby LP, Poulsen K, Reinholdt J, Kilian M. Resident aerobic microbiota of the adult human nasal cavity. APMIS. 108:663-675. [PubMed: 11200821]

5. Henriksson G, Helgeland L, Midtvedt T, Stierna P, Brandtzaeg P. Immune Response to Mycoplasma pulmonis in Nasal Mucosa Is Modulated by the Normal Microbiota. Ame J of Respir Cell Mol Biol. 2004; 31:657-662.

6. Frank DN, Feazel LM, Bessesen MT, Price CS, Janoff EN, Pace NR. The Human Nasal Microbiota and Staphylococcus aureus Carriage. PLoS ONE. 2010; 5:e10598. [PubMed: 20498722]

7. Lemon KP, Klepac-Ceraj V, Schiffer HK, Brodie EL, Lynch SV, Kolter R. Comparative Analyses of the Bacterial Microbiota of the Human Nostril and Oropharynx. mBio. 1

8. den Heijer CD, van Bijnen EM, Paget WJ, Pringle M, Goossens H, Bruggeman CA, Schellevis FG, Stobberingh EE. APRES Study Team. Prevalence and resistance of commensal Staphylococcus aureus, including meticillin-resistant $\mathrm{S}$ aureus, in nine European countries: a cross-sectional study. Lancet Infectious Disease. 2013; 13:409-415.

9. Yan M, Pamp SJ, Fukuyama J, Hwang PH, Cho D-Y, Holmes S, Relman DA. Nasal Microenvironments and Interspecific Interactions Influence Nasal Microbiota Complexity and S. aureus Carriage. Cell Host \& Microbe. 2013; 14:631-640. [PubMed: 24331461]

10. Suzaki H, Watanabe S, Pawankar R. Rhinosinusitis and asthma-microbiome and new perspectives. Curr Opin Allergy Clin Immunol. 2013; 13:45-49. [PubMed: 23128418]

11. Aurora R, Chatterjee D, Hentzleman J, Prasad G, Sindwani R, Sanford T. Contrasting the Microbiomes From Healthy Volunteers and Patients With Chronic Rhinosinusitis. JAMA Otolaryngol Head Neck Surg. 2013; 139:1328-1338. [PubMed: 24177790]

12. Tarran R, Redinbo MR. Mammalian short palate lung and nasal epithelial clone 1 (SPLUNC1) in $\mathrm{pH}$-dependent airway hydration. The International Journal of Biochemistry \& Cell Biology. 2014; 52:130-135. [PubMed: 24631954]

13. Garland AL, Walton WG, Coakley RD, Tan CD, Gilmore RC, Hobbs CA, Tripathy A, Clunes LA, Bencharit S, Stutts MJ, Betts L, Redinbo MR, Tarran R. Molecular basis for $\mathrm{pH}$-dependent mucosal dehydration in cystic fibrosis airways. Proc Natl Acad Sci U S A. 2013; 110:1597315978. [PubMed: 24043776]

14. Abreu NA, Nagalingam NA, Song Y, Roediger FC, Pletcher SD, Goldberg AN, Lynch SV. Sinus microbiome diversity depletion and Corynebacterium tuberculostearicum enrichment mediates rhinosinusitis. Science Translational Medicine. 2012; 4:151.

15. Boase S, Foreman A, Cleland E, Tan L, Melton-Kreft R, Pant H, Hu FZ, Ehrlich GD, Wormald PJ. The microbiome of chronic rhinosinusitis: culture, molecular diagnostics and biofilm detection. BMC Infect Dis. 2013; 13:210. [PubMed: 23656607]

16. Choi EB, Hong SW, Kim DK, Jeon SG, Kim KR, Cho SH, Gho YS, Jee YK, Kim YK. Decreased diversity of nasal microbiota and their secreted extracellular vesicles in patients with chronic rhinosinusitis based on a metagenomic analysis. Allergy. 2014; 69:517-526. [PubMed: 24611950]

17. Hobbs CA, Blanchard MG, Alijevic O, Tan CD, Kellenberger S, Bencharit S, Cao R, Kesimer M, Walton WG, Henderson AG, Redinbo MR, Stutts MJ, Tarran R. Identification of SPLUNC1's ENaC-inhibitory domain yields novel strategies to treat sodium hyperabsorption in cystic fibrosis airway cultures. Am J Physiol Lung Cell Mol Physiol. 2013; 305:L990-L1001. [PubMed: 24124190]

18. Ichinohe T, Pang IK, Kumamoto Y, Peaper DR, Ho JH, Murray TS, Iwasaki A. Microbiota regulates immune defense against respiratory tract influenza A virus infection. Proc Natl Acad Sci U S A. 2011; 108:5354. [PubMed: 21402903]

19. Olszak T, An D, Zeissig S, Vera MP, Richter J, Franke A, Glickman JN, Siebert R, Baron RM, Kasper DL, Blumberg RS. Microbial Exposure During Early Life Has Persistent Effects on Natural Killer T Cell Function. Science. 2012; 336:489-493. [PubMed: 22442383]

20. Huang, YJ.; Charlson, ES.; Collman, RG.; Colombini-Hatch, S.; Martinez, FD.; Senior, RM. The Role of the Lung Microbiome in Health and Disease. A National Heart, Lung, and Blood Institute Workshop Report. http://dx.doi.org/10.1164/rccm.201303-0488WS 
21. Segal LN, Alekseyenko AV, Clemente JC, Kulkarni R, Wu B, Chen H, Berger KI, Goldring RM, Rom WN, Blaser MJ, Weiden MD. Enrichment of lung microbiome with supraglottic taxa is associated with increased pulmonary inflammation. Microbiome. 2013; 1:19. [PubMed: 24450871]

22. Fodor AA, Klem ER, Gilpin DF, Elborn JS, Boucher RC, Tunney MM, Wolfgang MC. The Adult Cystic Fibrosis Airway Microbiota Is Stable over Time and Infection Type, and Highly Resilient to Antibiotic Treatment of Exacerbations. PLoS ONE. 2012; 7:e45001. [PubMed: 23049765]

23. Delhaes L, Monchy S, Fréalle E, Hubans C, Salleron J, Leroy S, Prevotat A, Wallet F, Wallaert B, Dei-Cas E, Sime-Ngando T, Chabé M, Viscogliosi E. The Airway Microbiota in Cystic Fibrosis: A Complex Fungal and Bacterial Community- Implications for Therapeutic Management. PLoS ONE. 2012; 7:e36313. [PubMed: 22558432]

24. Carmody LA, Zhao J, Schloss PD, Petrosino JF, Murray S, Young VB, Li JZ, LiPuma JJ. Changes in Cystic Fibrosis Airway Microbiota at Pulmonary Exacerbation. Annals of the American Thoracic Society. 2013; 10:179-183. [PubMed: 23802813]

25. Hauser PM, Bernard T, Greub G, Jaton K, Pagni M, Hafen GM. Microbiota Present in Cystic Fibrosis Lungs as Revealed by Whole Genome Sequencing. PLoS ONE. 2014; 9:e90934. [PubMed: 24599149]

26. Lieberman TD, Michel J-B, Aingaran M, Potter-Bynoe G, Roux D, Davis MR, Skurnik D, Leiby N, LiPuma JJ, Goldberg JB, McAdam AJ, Priebe GP, Kishony R. Parallel bacterial evolution within multiple patients identifies candidate pathogenicity genes. Nature genetics. 2011; 43:12751280. [PubMed: 22081229]

27. Lieberman TD, Flett KB, Yelin I, Martin TR, McAdam AJ, Priebe GP, Kishony R. Genetic variation of a bacterial pathogen within individuals with cystic fibrosis provides a record of selective pressures. Nature genetics. 2014; 46

28. Dickson RP, Erb-Downward JR, Huffnagle GB. The role of the bacterial microbiome in lung disease. Expert Review of Respiratory Medicine. 2013; 7:245-257. [PubMed: 23734647]

29. Sin D, Sze M, Hogg J. Bacterial microbiome of lungs in COPD. COPD. 2014:229.10.2147/ COPD.S38932

30. Erb-Downward JR, Thompson DL, Han MK, Freeman CM, McCloskey L, Schmidt LA, Young VB, Toews GB, Curtis JL, Sundaram B, Martinez FJ, Huffnagle GB. Analysis of the Lung Microbiome in the "Healthy" Smoker and in COPD. PLoS ONE. 2011; 6:e16384. [PubMed: 21364979]

31. Garzoni C, Brugger SD, Qi W, Wasmer S, Cusini A, Dumont P, Gorgievski- Hrisoho M, Muhlemann K, Garnier von C, Hilty M. Microbial communities in the respiratory tract of patients with interstitial lung disease. Thorax. 2013; 68:1150-1156. [PubMed: 23945167]

32. Molyneaux PL, Mallia P, Cox MJ, Footitt J, Willis-Owen SAG, Homola D, Trujillo-Torralbo MB, Elkin S, Kon OM, Cookson WOC, Moffatt MF, Johnston SL. Outgrowth of the Bacterial Airway Microbiome after Rhinovirus Exacerbation of Chronic Obstructive Pulmonary Disease. American Journal of Respiratory and Critical Care Medicine. 2013; 188:1224-1231. [PubMed: 23992479]

33. Rogers DGB, Zain DNMM, Bruce DKD, Burr DLD, Chen DAC, Rivett DDW, McGuckin PMA, Serisier DDJ. A Novel Microbiota Stratification System Predicts Future Exacerbations in Bronchiectasis. Annals of the American Thoracic Society. 11:496-503. [PubMed: 24592925]

34. Noverr MC, Noggle RM, Toews GB, Huffnagle GB. Role of Antibiotics and Fungal Microbiota in Driving Pulmonary Allergic Responses. Infect Immun. 2004; 72:4996-5003. [PubMed: 15321991]

35. Hilty M, Burke C, Pedro H, Cardenas P, Bush A, Bossley C, Davies J, Ervine A, Poulter L, Pachter L, Moffatt MF, Cookson WOC. Disordered Microbial Communities in Asthmatic Airways. PLoS ONE. 2010; 5:e8578. [PubMed: 20052417]

36. Ege MJ, Mayer M, Normand A-C, Genuneit J, Cookson WOCM, Braun- Fahrländer C, Heederik D, Piarroux R, Mutius von E. Exposure to Environmental Microorganisms and Childhood Asthma. N Engl J Med. 2011; 364:701-709. [PubMed: 21345099]

37. Blaser MJ. Equilibria of Humans and Our Indigenous Microbiota Affecting Asthma. Proc Am Thorac Soc. 2012; 9:69-71. [PubMed: 22550247] 
38. Lam D, Ng N, Lee S, Batzer G, Horner AA. Airway house dust extract exposures modify allergeninduced airway hypersensitivity responses by TLR4-dependent and independent pathways. J Immunol. 2008; 181:2925-2932. [PubMed: 18684984]

39. Fujimura KE, Demoor T, Rauch M, Faruqi AA, Jang S, Johnson CC, Boushey HA, Zoratti E, Ownby D, Lukacs NW, Lynch SV. House dust exposure mediates gut microbiome Lactobacillus enrichment and airway immune defense against allergens and virus infection. Proc Natl Acad Sci U S A. 2014; 111:805. [PubMed: 24344318]

40. Trompette A, Gollwitzer ES, Yadava K, Sichelstiel AK, Sprenger N, Ngom-Bru C, Blanchard C, Junt T, Nicod LP, Harris NL, Marsland BJ. Gut microbiota metabolism of dietary fiber influences allergic airway disease and hematopoiesis. Nature Medicine. 2014; 20:159-166.

41. Segata N, Haake SK, Mannon P, Lemon KP, Waldron L, Gevers D, Huttenhower C, Izard J. Composition of the adult digestive tract bacterial microbiome based on seven mouth surfaces, tonsils, throat and stool samples. Genome Biology. 2012; 13:R42. [PubMed: 22698087]

42. Faith JJ, Guruge JL, Charbonneau M, Subramanian S, Seedorf H, Goodman AL, Clemente JC, Knight R, Heath AC, Leibel RL, Rosenbaum M, Gordon JI. The long-term stability of the human gut microbiota. Science. 2013; 341:1237439. [PubMed: 23828941]

43. Turnbaugh PJ, Hamady M, Yatsunenko T, Cantarel BL, Duncan A, Ley RE, Sogin ML, Jones WJ, Roe BA, Affourtit JP, Egholm M, Henrissat B, Heath AC, Knight R, Gordon JI. A core gut microbiome in obese and lean twins. Nature. 2008; 457:480-484. [PubMed: 19043404]

44. Sonnenburg ED, Zheng H, Joglekar P, Higginbottom SK, Firbank SJ, Bolam DN, Sonnenburg JL. Specificity of Polysaccharide Use in Intestinal Bacteroides Species Determines Diet-Induced Microbiota Alterations. Cell. 2010; 141:1241-1252. [PubMed: 20603004]

45. Marcobal A, Barboza M, Sonnenburg ED, Pudlo N, Martens EC, Desai P, Lebrilla CB, Weimer BC, Mills DA, German JB, Sonnenburg JL. Bacteroides in the Infant Gut Consume Milk Oligosaccharides via Mucus-Utilization Pathways. Cell Host \& Microbe. 2011; 10:507-514. [PubMed: 22036470]

46. Koropatkin NM, Cameron EA, Martens EC. How glycan metabolism shapes the human gut microbiota. Nat Rev Micro. 201210.1038/nrmicro2746

47. Cho I, Yamanishi S, Cox L, Methé BA, Zavadil J, Li K, Gao Z, Mahana D, Raju K, Teitler I, Li H, Alekseyenko AV, Blaser MJ. Antibiotics in early life alter the murine colonic microbiome and adiposity. Nature. 2012; 488:621-626. [PubMed: 22914093]

48. Kamada N, Kim YG, Sham HP, Vallance BA, Puente JL, Martens EC, Nunez G. Regulated Virulence Controls the Ability of a Pathogen to Compete with the Gut Microbiota. Science. 2012; 336:1325-1329. [PubMed: 22582016]

49. Ng KM, Ferreyra JA, Higginbottom SK, Lynch JB, Kashyap PC, Gopinath S, Naidu N, Choudhury B, Weimer BC, Monack DM, Sonnenburg JL. Microbiota-liberated host sugars facilitate postantibiotic expansion of enteric pathogens. Nature. 2013; 502:96-99. [PubMed: 23995682]

50. Kashyap PC, Marcobal A, Ursell LK, Larauche M, Duboc H, Earle KA, Sonnenburg ED, Ferreyra JA, Higginbottom SK, Million M, Tache Y, Pasricha PJ, Knight R, Farrugia G, Sonnenburg JL. Complex Interactions Among Diet, Gastrointestinal Transit, and Gut Microbiota in Humanized Mice. Gastroenterology. 2013; 144:967-977. [PubMed: 23380084]

51. Larsbrink J, Rogers TE, Hemsworth GR, McKee LS, Tauzin AS, Spadiut O, Klinter S, Pudlo NA, Urs K, Koropatkin NM, Creagh AL, Haynes CA, Kelly AG, Cederholm SN, Davies GJ, Martens EC, Brumer H. A discrete genetic locus confers xyloglucan metabolism in select human gut Bacteroidetes. Nature. 2014; 506:498-502. [PubMed: 24463512]

52. David LA, Maurice CF, Carmody RN, Gootenberg DB, Button JE, Wolfe BE, Ling AV, Devlin AS, Varma Y, Fischbach MA, Biddinger SB, Dutton RJ, Turnbaugh PJ. Diet rapidly and reproducibly alters the human gut microbiome. Nature. 2013; 505:559-563. [PubMed: 24336217]

53. Craciun S, Balskus EP. Microbial conversion of choline to trimethylamine requires a glycyl radical enzyme. Proc Natl Acad Sci U S A. 2012; 109:21307-21312. [PubMed: 23151509]

54. Bennett BJ, Vallim TQ, de A, Wang Z, Shih DM, Meng Y, Gregory J, Allayee H, Lee R, Graham M, Crooke R, Edwards PA, Hazen SL, Lusis AJ. Trimethylamine-N-Oxide, a Metabolite Associated with Atherosclerosis, Exhibits Complex Genetic and Dietary Regulation. Cell Metabolism. 2013; 17:49-60. [PubMed: 23312283] 
55. Tang WHW, Wang Z, Levison BS, Koeth RA, Britt EB, Fu X, Wu Y, Hazen SL. Intestinal Microbial Metabolism of Phosphatidylcholine and Cardiovascular Risk. N Engl J Med. 2013; 368:1575-1584. [PubMed: 23614584]

56. Koeth RA, Wang Z, Levison BS, Buffa JA, Org E, Sheehy BT, Britt EB, Fu X, Wu Y, Li L, Smith JD, DiDonato JA, Chen J, Li H, Wu GD, Lewis JD, Warrier M, Brown JM, Krauss RM, Tang WHW, Bushman FD, Lusis AJ, Hazen SL. Intestinal microbiota metabolism of 1-carnitine, a nutrient in red meat, promotes atherosclerosis. Nature Medicine. 2013; 19:576-585.

57. Gerhard Rogler G, Haller D, Jobin C. Microbiota in Chronic Mucosal Inflammation. International Journal of Inflammation. 2010; 2010:1-2.

58. Wlodarska M, Thaiss CA, Nowarski R, Henao-Mejia J, Zhang J-P, Brown EM, Frankel G, Levy M, Katz MN, Philbrick WM, Elinav E, Finlay BB, Flavell RA. NLRP6 Inflammasome Orchestrates the Colonic Host-Microbial Interface by Regulating Goblet Cell Mucus Secretion. Cell. 2014; 156:1045-1059. [PubMed: 24581500]

59. Olszak T, Neves JF, Dowds CM, Baker K, Glickman J, Davidson NO, Lin C-S, Jobin C, Brand S, Sotlar K, Wada K, Katayama K, Nakajima A, Mizuguchi H, Kawasaki K, Nagata K, Müller W, Snapper SB, Schreiber S, Kaser A, Zeissig S, Blumberg RS. Protective mucosal immunity mediated by epithelial CD1d and IL-10. Nature. 2014; 509:497-502. [PubMed: 24717441]

60. Wieland Brown LC, Penaranda C, Kashyap PC, Williams BB, Clardy J, Kronenberg M, Sonnenburg JL, Comstock LE, Bluestone JA, Fischbach MA. Production of a-Galactosylceramide by a Prominent Member of the Human Gut Microbiota. PLoS Biol. 2013; 11:e1001610. [PubMed: 23874157]

61. Mortha A, Chudnovskiy A, Hashimoto D, Bogunovic M, Spencer SP, Belkaid Y, Merad M. Microbiota-Dependent Crosstalk Between Macrophages and ILC3 Promotes Intestinal Homeostasis. Science. 2014; 343:1249288-1249288. [PubMed: 24625929]

62. Kanther M, Tomkovich S, Xiaolun S, Grosser MR, Koo J, Flynn EJ III, Jobin C, Rawls JF. Commensal microbiota stimulate systemic neutrophil migration through induction of Serum amyloid A. Cell Microbiol. 2014; 16:1053-1067. [PubMed: 24373309]

63. Devkota S, Wang Y, Musch MW, Leone V, Fehlner-Peach H, Nadimpalli A, Antonopoulos DA, Jabri B, Chang EB. Dietary-fat-induced taurocholic acid promotes pathobiont expansion and colitis in Il10-/- mice. Nature. 2012; 487:104-108. [PubMed: 22722865]

64. Arthur JC, Perez-Chanona E, Muhlbauer M, Tomkovich S, Uronis JM, Fan TJ, Campbell BJ, Abujamel T, Dogan B, Rogers AB, Rhodes JM, Stintzi A, Simpson KW, Hansen JJ, Keku TO, Fodor AA, Jobin C. Intestinal Inflammation Targets Cancer-Inducing Activity of the Microbiota. Science. 2012; 338:120-123. [PubMed: 22903521]

65. Hsiao EY, McBride SW, Hsien S, Sharon G, Hyde ER, McCue T, Codelli JA, Chow J, Reisman SE, Petrosino JF, Patterson PH, Mazmanian SK. Microbiota Modulate Behavioral and Physiological Abnormalities Associated with Neurodevelopmental Disorders. Cell. 2013; 155:1451-1463. [PubMed: 24315484]

66. Sousa T, Paterson R, Moore V, Carlsson A, Abrahamsson B, Basit AW. The gastrointestinal microbiota as a site for the biotransformation of drugs. International Journal of Pharmaceutics. 2008; 363:1-25. [PubMed: 18682282]

67. Maurice CF, Haiser HJ, Turnbaugh PJ. Xenobiotics Shape the Physiology and Gene Expression of the Active Human Gut Microbiome. Cell. 2013; 152:39-50. [PubMed: 23332745]

68. Haiser HJ, Gootenberg DB, Chatman K, Sirasani G, Balskus EP, Turnbaugh PJ. Predicting and Manipulating Cardiac Drug Inactivation by the Human Gut Bacterium Eggerthella lenta. Science. 2013; 341:295-298. [PubMed: 23869020]

69. Wallace BD, Wang H, Lane KT, Scott JE, Orans J, Koo JS, Venkatesh M, Jobin C, Yeh L-A, Mani S, Redinbo MR. Alleviating cancer drug toxicity by inhibiting a bacterial enzyme. Science. 2010; 330:831-835. [PubMed: 21051639]

70. Roberts AB, Wallace BD, Venkatesh MK, Mani S, Redinbo MR. Molecular Insights into Microbial $\beta$-Glucuronidase Inhibition to Abrogate CPT-11 Toxicity. Mol Pharmacol. 2013; 84:208-217. [PubMed: 23690068]

71. Wallace BD, Redinbo MR. The human microbiome is a source of therapeutic drug targets. Current Opinion in Chemical Biology. 2013; 17:379-384. [PubMed: 23680493] 
72. Boelsterli UA, Redinbo MR, Saitta K. Multiple NSAID-induced hits injure the small intestine: Underlying mechanisms and novel strategies. Toxicological Sciences. 2012; 131:654-667. [PubMed: 23091168]

73. LoGuidice A, Wallace BD, Bendel L, Redinbo MR, Boelsterli UA. Pharmacologic targeting of bacterial $\beta$-glucuronidase alleviates nonsteroidal antiinflammatory drug-induced enteropathy in mice. J Pharmacol Exp Ther. 2012; 341:447-454. [PubMed: 22328575]

74. Saitta KS, Zhang C, Lee KK, Fujimoto K, Redinbo MR, Boelsterli UA. Bacterial BetaGlucuronidase Inhibition Protects Mice Against Enteropathy Induced by Indomethacin, Ketoprofen, or Diclofenac: Mode of Action and Pharmacokinetics. Xenobiotica. 2014; 44:28-35. [PubMed: 23829165]

75. Mani S, Boelsterli UA, Redinbo MR. Interrogating and Modulating Mammalian-Microbial Communication for Improved Health. Annual Review of Pharmacology and Toxicology. 2014; 55:559-580.

76. Iida N, Dzutsev A, Stewart CA, Smith L, Bouladoux N, Weingarten RA, Molina DA, Salcedo R, Back T, Cramer S, Dai RM, Kiu H, Cardone M, Naik S, Patri AK, Wang E, Marincola FM, Frank KM, Belkaid Y, Trinchieri G, Goldszmid RS. Commensal Bacteria Control Cancer Response to Therapy by Modulating the Tumor Microenvironment. Science. 2013; 342:967-970. [PubMed: 24264989]

77. Viaud S, Saccheri F, Mignot G, Yamazaki T, Daillere R, Hannani D, Enot DP, Pfirschke C, Engblom C, Pittet MJ, Schlitzer A, Ginhoux F, Apetoh L, Chachaty E, Woerther PL, Eberl G, Berard M, Ecobichon C, Clermont D, Bizet C, Gaboriau-Routhiau V, Cerf-Bensussan N, Opolon P, Yessaad N, Vivier E, Ryffel B, Elson CO, Dore J, Kroemer G, Lepage P, Boneca IG, Ghiringhelli F, Zitvogel L. The Intestinal Microbiota Modulates the Anticancer Immune Effects of Cyclophosphamide. Science. 2013; 342:971-976. [PubMed: 24264990]

78. Venkatesh M, Mukherjee S, Wang H, Sun K, Benechet AP, Qiu Z, Maher L, Redinbo MR, Phillips RS, Fleet JC, Kortagere S, Mukherjee P, Fasano A, Dumas ME, Le Ven J, Nicholson JK, Khanna KM, Mani S. Symbiotic Bacterial Metabolites Regulate Gastrointestinal Barrier Function via the Xenobiotic Sensor PXR and Toll-like Receptor 4. Immunity. 2014; 41:296-310. [PubMed: 25065623]

79. Turnbaugh PJ, Henrissat B, Gordon JI. Viewing the human microbiome through three-dimensional glasses: integrating structural and functional studies to better define the properties of myriad carbohydrate-active enzymes. Acta Crystallographica Section F: Structural Biology and Crystallization Communications. 2010; 66:1261. 


\section{HIGHLIGHTS}

- Complex symbioses exist between human systems and the microbiota

- The most intimate contacts between domains of life occur at the mucosal epithelia

- Three mucosal compartments are considered: the nasal-sinuses, lungs, and intestines

- New opportunities for the rational modulation of the microbiota are reviewed 


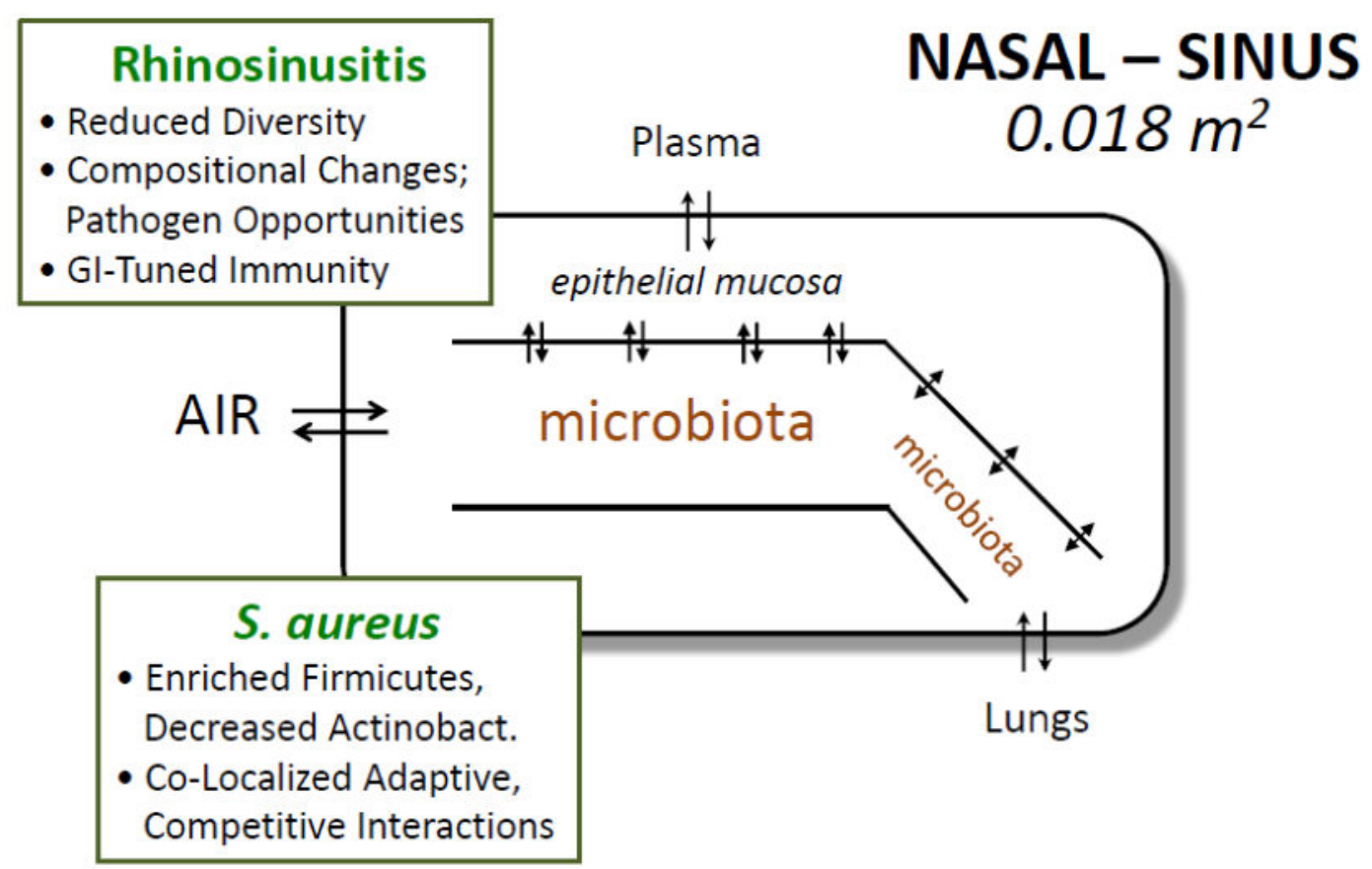

Figure 1.

The small $18 \mathrm{~cm}^{2}$ surface area of the Nasal-Sinus Compartment is skin-like at the nostrils but is then lined by mucosal epithelia (mucosa) and colonized with microbiota (orange). Air, including particulate and some biological matter, is passed through on its way to the lungs, the major output, although some mucus-entrapped matter is passed to the gastrointestinal tract. Small arrows across the mucosa indicate local absorption and secretion, including mucus delivery. Chemicals absorbed across this still external nasal-sinus mucosa then enter the human body, passing through the plasma and into the heart for circulation. Diseases associated with the nasal-sinus compartment represented are Staphylococcus aureus infection and rhinosinusitis, with some features highlighted (see text for details). 


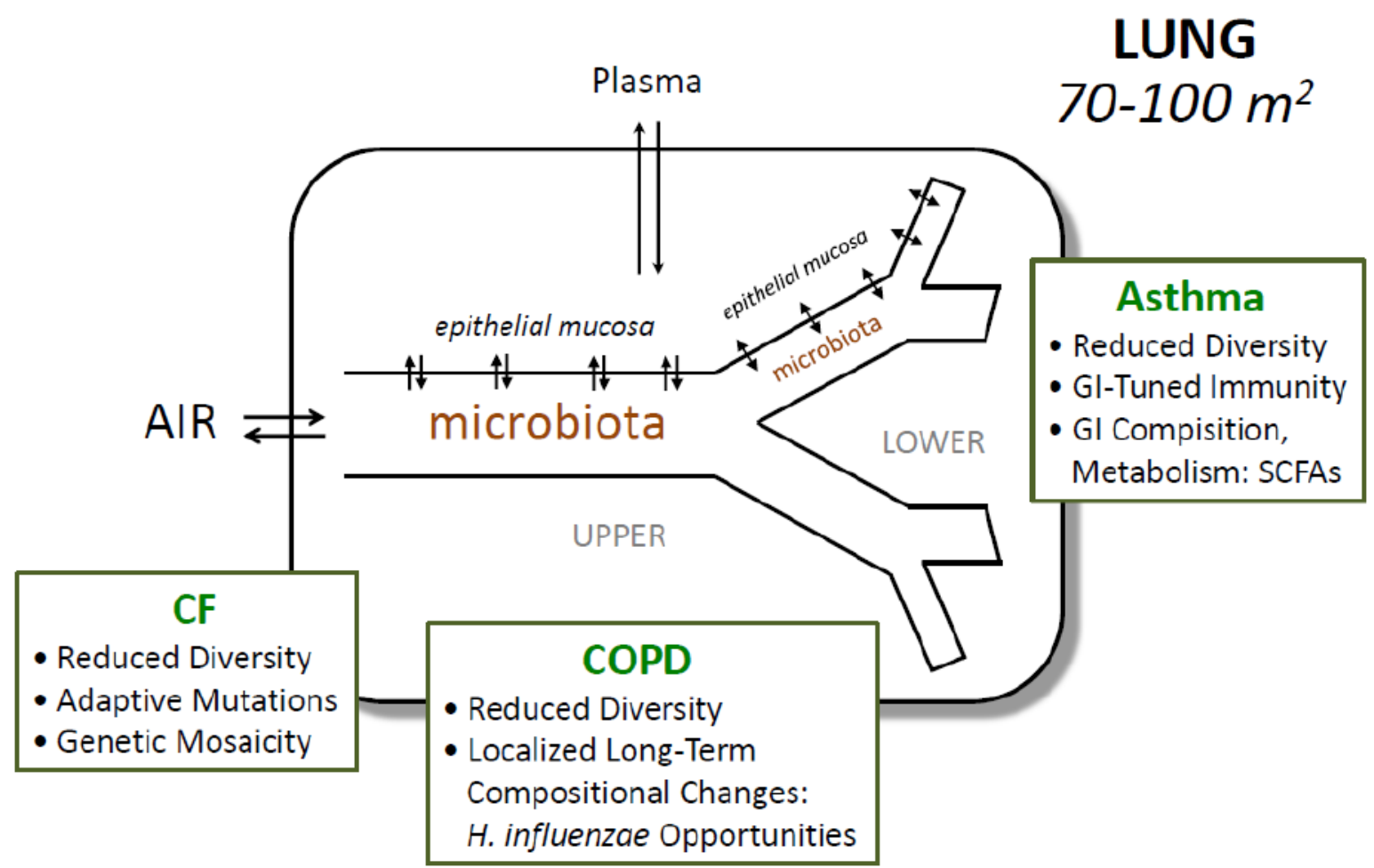

Figure 2.

The larger 70-100 $\mathrm{m}^{2}$ surface area of the Lung Compartment is composed of the UPPER more microbial colonized airways and the LOWER airways that are non-sterile but contain microbiota (orange). Local exchange of materials across the mucosal epithelia that line this compartment (mucosa) are indicated by the small arrows, and materials absorbed into the human body via this route, including $\mathrm{O}_{2}$, are carried by the plasma to the heart for circulation. Microbiota features of the lung diseases cystic fibrosis (CF), chronic obstructive pulmonary disorder (COPD), and asthma associated are highlighted, and are elaborated in the text. 


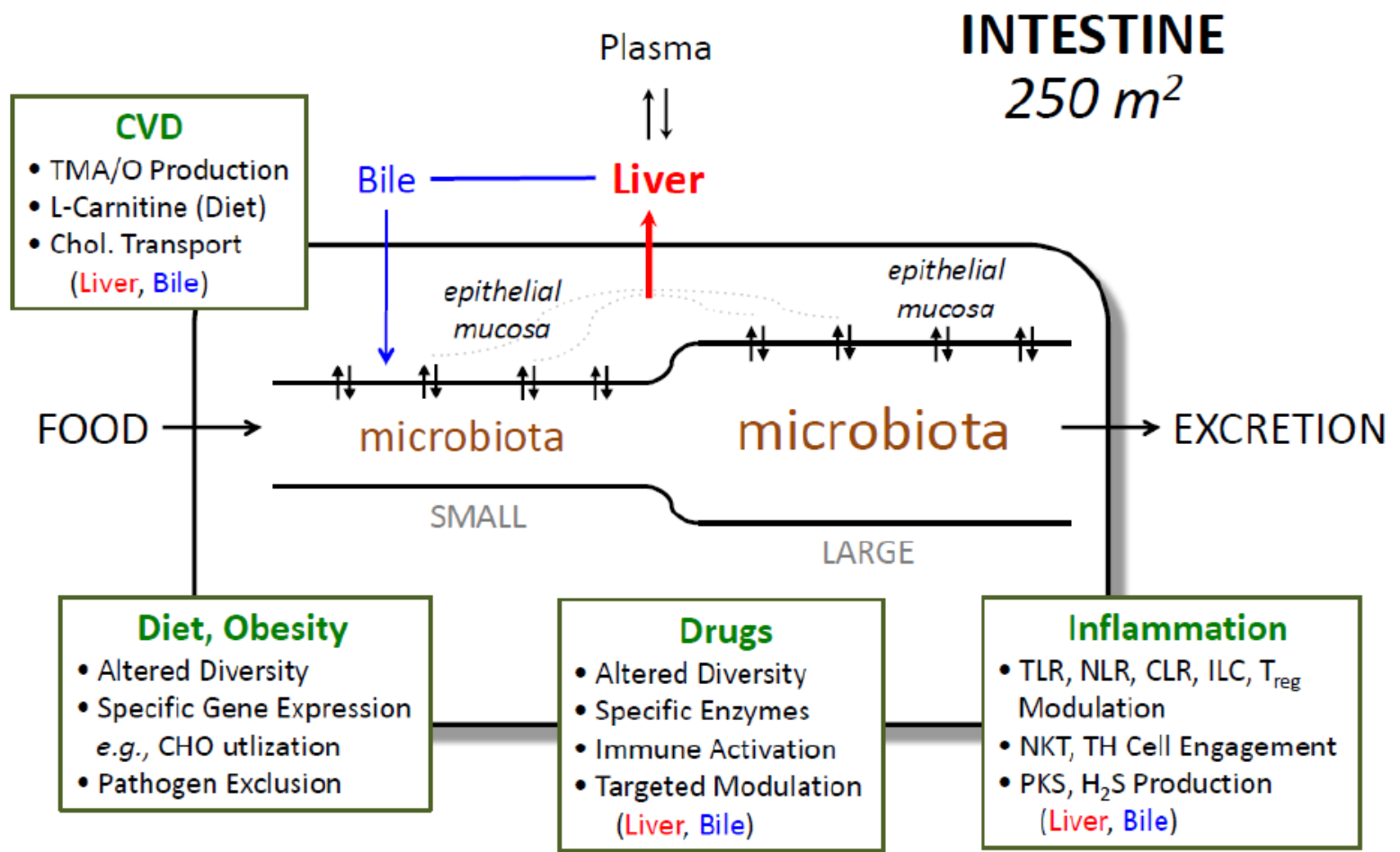

Figure 3.

The vast $250 \mathrm{~m}^{2}$ surface area of the Intestinal Compartment is colonized by a diverse community of trillions of commensal bacterial cells (orange) and lined by mucosal epithelia (mucosa) unique in structure and function to each region of the GI tract. Local exchange across the mucosa are indicated by small arrows. Distinct from the other major mucosal tissues presented here, materials absorbed from the intestinal compartment pass via the portal vein to the liver (red) prior to potentially reaching systemic circulation. Furthermore, this compartment is also distinct in having two major input sources, the food and other materials from the oral cavity, and the liver-generated bile (blue) and other secretions from the local organs like the pancreas and gall bladder. Features associated with the microbiota and diet and obesity, cardiovascular disease (CVD), inflammation, and drug toxicity are highlighted. Some links to the unique roles the bile and liver play in sending and receiving, respectively, material from the GI are noted. As indicated, the GI microbiota also impact the other compartments considered via the immune system. 